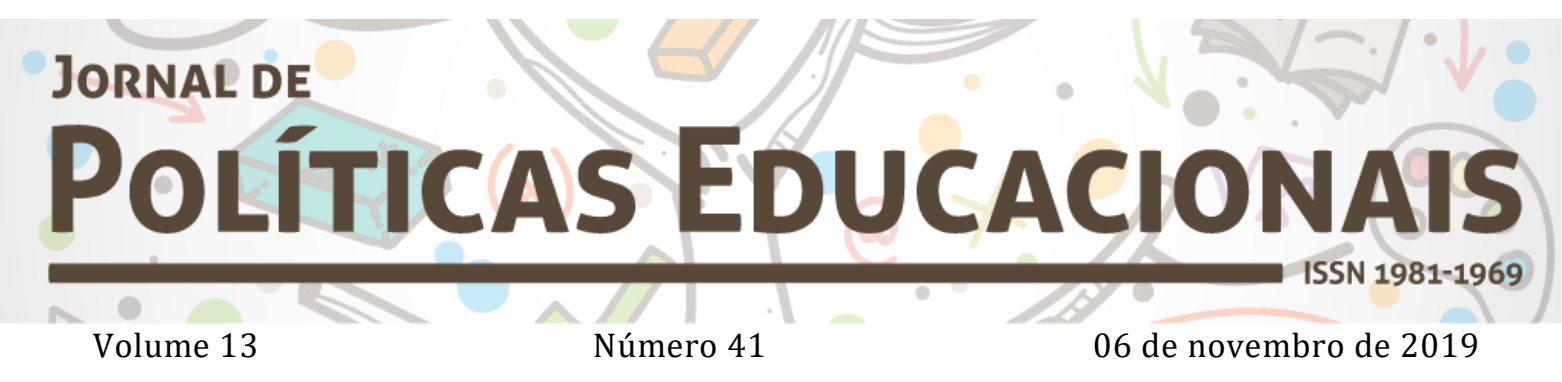

\title{
Educação escolar indígena: o cenário das políticas públicas no extremo ocidente do Brasil
}

\author{
Indigenous school education: the scenario of public policies in the \\ extreme west of Brazil
}

\section{Educación escolar indígena: el escenario de las políticas públicas en el extremo occidente de Brasil}

José Alessandro Cândido da Silva ${ }^{1}$

Citação: SILVA, J.A.C.da. Educação escolar indígena: o cenário das políticas públicas no extremo ocidente do Brasil V. 13, n. 41. Novembro de 2019.

http://10.5380/jpe.v13i0.67837

\begin{abstract}
Resumo:
0 artigo analisa uma das políticas educacionais para a diversidade, a de Educação Escolar Indígena. 0 estudo foca em problemas na sua efetivação, permitindo-nos refletir sobre seu desenvolvimento no Acre. Aponta os embates na sua definição, destacando o papel dos agentes envolvidos desde a formulação até a execução nos contextos formais. Toma como base metodológica o Ciclo de Políticas. Das questões resultantes, destacamos o fato de as propostas e práticas de EEI no Acre terem transformado os direitos educativos indígenas em obrigações de Estado, mas perdendo seu caráter de produção coletiva e autônoma.
\end{abstract}

Palavras-chave: Políticas Educacionais. Educação Escolar Indígena. Acre.

\begin{abstract}
The article analyzes one of the educational policies for diversity: Indigenous School Education. The study focuses on problems in its implementation, allowing us to reflect on its development in Acre. It points out the clashes in its definition, highlighting the role of the agents involved from formulation to execution in formal contexts. Its methodological basis is the Policy Cycle. From the resulting issues, we highlight the fact that the proposals and practices of ISS in Acre have transformed indigenous educational rights into state obligations, but losing their character of collective and autonomous production.
\end{abstract}

Keywords: Educational Policies. Indigenous School Education. Acre.

1 Doutor em Educação. Professor do Magistério Superior na UFAC - Campus Floresta. Orcid: https://orcid.org/0000-0002-5230-0449. E-mail: alessandroczs@bol.com.br 


\section{Resumen}

Este artículo analiza una de las políticas educativas para la diversidad, la de la educación escolar indígena. El estudio se centra en problemas en su implementación, lo que nos permite reflexionar sobre su desarrollo en Acre. Señala los enfrentamientos en su definición, destacando el papel de los agentes involucrados desde la formulación hasta la ejecución en contextos formales. Su base metodológica es el Ciclo de Políticas. De los problemas resultantes, destacamos el hecho de que las propuestas y prácticas de ISS en Acre han transformado los derechos educativos indígenas en obligaciones estatales, pero perdiendo su carácter de producción colectiva y autónoma.

Palabras clave: Políticas educativas. Educación escolar indígena. Acre

\section{Introdução}

Esta produção teve como foco a reflexão acerca das políticas públicas educacionais indígenas implementadas e desenvolvidas no Acre, unidade federativa precursora no processo de organização da Educação Escolar Indígena (EEI). Nesse espaço geográfico foram desenvolvidas iniciativas educacionais que historicamente definiram e marcaram essas discussões ao lado de outras experiências educacionais indígenas do país. Essas razões nos permitiram voltar o olhar sobre o complexo desenvolvimento de tais políticas, para as diferentes e por vezes conflitantes vozes dos atores sociais e das instituições que as propõem e concretizam.

0 reconhecimento dos direitos dos povos indígenas às terras que tradicionalmente ocupam, para garantirem sua reprodução e perpetuação física e cultural, é um dos direitos consagrados na Constituição Federal, promulgada em 1988, que também propõe garantias aos povos indígenas de manterem suas identidades diferenciadas, preservando suas línguas, culturas, tradições, modos de ser e de pensar. Nas três últimas décadas, verificou-se uma mudança de paradigmas na relação com esses povos, por meio de importantes e significativas "transformações que ocorreram tanto na legislação quanto na política governamental em relação a esses povos no Brasil. Uma das áreas em que essas mudanças mais se realizaram foi na política de Educação Escolar Indígena" (GRUPIONI, 2005, p. 46).

Historicamente, a introdução da escola entre os povos indígenas serviu de instrumento de imposição de valores alheios e de negação de identidades diferenciadas, por meio de diferentes processos, como a catequização e a integração forçada dos índios à "comunhão nacional". No entanto, em anos recentes, a escola ganhara um novo sentido para tais povos, tornando-se um meio de acesso aos conhecimentos científicos e de valorização e sistematização de saberes tradicionais e passando a desenvolver, na contemporaneidade, uma demanda de projetos dos próprios povos indígenas 
Diante da ressignificação da escola para muitas comunidades étnicas, profundas problemáticas ainda desafiam educadores e pesquisadores do campo, no sentido de melhor compreender e desenvolver os processos educacionais de forma adequada às comunidades indígenas. Entre essas questões, destacamos a inclusão das escolas indígenas nos sistemas oficiais de ensino em todo o país que é relativamente recente e ainda se encontra em difícil processo de construção, enfrentando problemas e buscando soluções condizentes com o direito constitucional de operar uma educação escolar específica e diferenciada.

A temática da Educação Escolar Indígena vem ganhando espaço em muitos debates no Brasil com a finalidade de se refletir com maior propriedade sua natureza, mas, sobretudo, de transformar para melhor essa realidade social, através da definição de políticas públicas educacionais que sejam frutos de uma construção coletiva. Isso significaria contar com representantes de cada etnia como forma de elaborar modelos educacionais distintos que superem os desafios que a diversidade cultural nos tem trazido.

Vivemos ainda hoje um momento de transição, definição e ajustes do sistema educacional brasileiro em virtude da exigência legal (Artigo 210 da Constituição Federal de 1988, com detalhamento na Lei de Diretrizes e Bases da Educação Nacional de 1996) de mudanças a serem delineadas pela proposta de uma EEI diferenciada, específica, intercultural, de qualidade e bilíngue.

A perspectiva deste estudo traz o discurso da educação diferenciada como um dos direitos dos povos indígenas que se estrutura pela negação da escola indígena vigente em vários lugares do Brasil (identificada como não indígena) e pela afirmação de um novo conjunto de premissas que orientam sua transformação. É, assim, pelo rechaço de práticas e ideias que esse discurso se constrói como inovador e busca alcançar legitimidade. Grupioni, ao referir-se aos princípios da escola indígena, aponta:

Em contraposição a uma escola que se constituía pela imposição do ensino da língua portuguesa, pelo acesso à cultura nacional e pela perspectiva da integração é que se molda um outro modelo de como deveria ser a nova escola indígena, caracterizada como uma escola comunitária (na qual a comunidade indígena deveria ter papel preponderante, diferenciada (das demais escolas brasileiras), específica (própria a cada povo indígena onde fosse instalada), intercultural (no estabelecimento de um diálogo entre conhecimentos ditos universais e indígenas) e bilíngue (com a consequente valorização das línguas maternas e não só de acesso à língua nacional (GRUPIONI, 2008, p. 37). 
Esse novo conjunto de ideias e práticas, ainda que propagado em sua generalidade, passa a estar no cerne de um discurso que se contrapõe a processos que vinham de longa data e que se expressavam tanto nos modelos da escola missionária como da escola ofertada por outras instituições governamentais, todas civilizadoras, que passam a ser combatidos enquanto modelos que deveriam ser superados. Algumas dessas escolas ainda continuam esse processo.

Nesse contexto é que se insere essa proposta de refletir e conhecer mais profundamente as políticas públicas educacionais indígenas implementadas e desenvolvidas no estado acreano. E por que falar dessa parte do território brasileiro? 0 Acre é uma unidade federativa precursora no processo de reflexão e organização da EEI, sobretudo, na formação de docentes indígenas, em nível médio (magistério Indígena), processo que buscava garantir aos professores indígenas formação inicial e continuada que considerasse e respeitasse suas realidades particulares, mesmo antes de se estabelecer os seus marcos legais no país.

Partindo desse contexto, este estudo objetivou compreender o processo de implementação e desenvolvimento das políticas públicas educacionais indígenas no estado do Acre com ênfase na formação de professores indígenas a partir do final da década de 1990, considerando os embates travados na redefinição da educação escolar. Em decorrência desse propósito, problematizamos a temática buscando compreender como as ações desenvolvidas pelas políticas de EEI no Acre se definem à luz do proposto pela legislação no Brasil. Para isso, lançamos mão de dados sobre os programas de formação de professores indígenas no estado diante dos desafios e demandas da atuação de docentes nas aldeias da região e, ainda, sobre o papel do movimento indígena perante as tensões travadas entre professores indígenas e o Estado em relação às ações públicas para a Educação Escolar Indígena (SILVA, 2013). A execução de ações públicas relativas ao processo educacional em áreas acreanas habitadas por populações tradicionais e suas trajetórias históricas são episódios cujos registros se apresentam pouco conhecidos, sobretudo, pela sua escassez.

A abordagem metodológica adotada apontou a possibilidade de ultrapassarmos os conflitos entre pesquisa qualitativa e quantitativa, tendo em vista que elas estão intimamente relacionadas (ANDRÉ, 2002). O levantamento de informações se deu por meio da apropriação de um corpus documental produzido por grupos e organizações envolvidas na defesa da escola indígena. Os documentos pesquisados consistiram em 
registros de relatórios, bem como em documentos oficiais da Comissão Pró-Índio/Acre CPI/AC, da Secretaria de Estado da Educação, Cultura e Esporte e da Organização dos Professores Indígenas do Acre/OPIAC. Coletamos, ainda, informações a partir de entrevistas realizadas com egressos do Curso de Licenciatura Indígena da UFAC, os quais são professores em suas comunidades e sujeitos que protagonizaram o processo de criação da Educação Escolar Indígena no estado (SILVA, 2014).

A abordagem teórico-metodológica adotada ofereceu pressupostos para guiar o estudo e sustentar a análise decorrente. Em geral, tanto no campo das políticas públicas quanto no das políticas educacionais, alguns teóricos brasileiros têm buscado debater e sintetizar questões teórico-metodológicas na análise de políticas. Compreendemos que a discussão sobre essas questões é tão polêmica quanto importante e que:

[...] no Brasil são ainda raros os trabalhos que se propuseram a discutir abordagens metodológicas para a pesquisa sobre políticas públicas e educacionais. [...] e que a maneira como um pesquisador encara a política educacional influencia o tipo de investigação que se propõe a realizar (MAINARDES, 2009, p. 5).

A pesquisa de políticas educacionais é um campo relativamente novo e ainda não consolidado em termos de referenciais analíticos consistentes. Apesar disso, pode-se afirmar a partir das discussões na área das políticas que se trata de um campo em permanente construção e expansão. Desse modo, após leituras e discussões sobre a importância das pesquisas no campo das políticas públicas educacionais e considerando os diversos movimentos que tornam determinada política relevante a ponto de ser homologada e efetivada, optamos por adotar a abordagem do Ciclo de Políticas de Stephen Ball e Richard Bowe, apresentada por Jefferson Mainardes (2006; 2009). Essa abordagem lança a ideia de que pensar as políticas educacionais envolve compreender desde sua fase de formulação até a sua efetivação, sendo que toda essa trajetória é permeada de relações de poder, fato essencial a ser considerado por quem formula, executa e pesquisa.

A abordagem do Ciclo de Políticas de Stephen Ball e Richard Bowe:

[...] destaca a natureza complexa e controversa da política educacional, enfatiza os processos micro políticos e a ação dos profissionais que lidam com as políticas no nível local e indica a necessidade de se articularem os processos macro e micro na análise de políticas educacionais (MAINARDES, 2006a, p. 95). 
Enquanto forma de pensamento, o Ciclo de Políticas é um subsídio importante para compreender as políticas. Nele, os autores propõem a consideração de cinco contextos, a saber: Contexto de Influência, Contexto da Produção de Texto, Contexto da Prática, Contexto dos Resultados/Efeitos e Contexto de Estratégia Política. Esses contextos estão inter-relacionados, por isso não precisam ser analisados de forma linear.

O Contexto de Influência pode ser compreendido como o início das políticas públicas, resultante dos movimentos e embates que permeiam a criação da política. No caso específico desta pesquisa, estariam envolvidas de forma direta nesse contexto todas as lutas dos movimentos indígenas e indigenistas possíveis de serem identificadas ao longo da história da EEI, que, após muitos embates e resistências ao modelo escolar ocidentalizado proposto pelo Estado brasileiro, conquistaram mudanças, fazendo a educação escolar para esses povos assumir o caráter diferenciado do modelo ocidental, levando a escola a tornar-se um instrumento a serviço da manutenção e desenvolvimento de suas culturas e tradições. Além disso, podemos incluir os movimentos realizados por organizações representativas desses povos no Acre que lutaram pela garantia de uma escola diferenciada como elemento de política pública.

Segundo Mainardes:

[...] É nesse contexto que grupos de interesse disputam para influenciar a definição das finalidades sociais da educação e do que significa ser educado. Atuam nesse contexto as redes sociais dentro e em torno de partidos políticos, do governo e do processo legislativo. É também nesse contexto que os conceitos adquirem legitimidade e formam um discurso de base para a política. [...] Além disso, há um conjunto de arenas públicas mais formais, tais como comissões e grupos representativos, que podem ser lugares de articulação de influência (MAINARDES, 2006b, p. 51).

O Contexto da Produção de texto representa o texto político. De acordo com Mainardes, "os textos políticos normalmente estão articulados com a linguagem do interesse público mais geral" (MAINARDES, 2006b, p. 53). Focalizando nosso objeto de estudo, acreditamos que a preocupação com esse contexto é identificada através da análise dos documentos nacionais e estaduais direcionados a EEI, além dos documentos organizados pela CPI/AC e OPIAC sobre essa proposta de educação.

0 terceiro ponto refere-se ao Contexto da Prática. Este pode ser caracterizado como a efetivação das políticas. As políticas não são simplesmente transpostas aos 
sistemas e unidades educativas, pelo contrário, elas são interpretadas e em alguns casos recriadas a partir das vivências e conhecimentos dos sujeitos envolvidos no processo.

Para Mainardes, é nesse contexto que a política pode gerar efeitos, consequências e transformações (MAINARDES, 2006a). Portanto, no Contexto da Prática, enfatizamos os discursos produzidos nas documentações produzidas pelo movimento indígena, pelas organizações indigenistas, os dados a respeito da formação inicial e continuada, a aquisição de material didático e demais informações coletadas a partir das entrevistas com os gestores do sistema educacional, pois a partir desse contexto são propostas as políticas para as unidades escolares indígenas. Considerando a abordagem teóricometodológica do Ciclo de Políticas, destacamos que todos os profissionais da educação são atores desse processo de interpretação/sistematização/concretização das políticas educacionais.

O quarto Contexto é o dos Resultados/Efeitos. Através dele, podemos verificar os impactos das políticas. Em nossa pesquisa, os impactos serão analisados através dos dados expostos pelos professores indígenas a serem entrevistados, cotejados com as ações desenvolvidas pela Secretaria de Educação. Conforme Mainardes:

[...] o contexto dos resultados ou efeitos - preocupa-se com questões de justiça, igualdade e liberdade individual. A ideia de que as políticas têm efeitos, em vez de simplesmente resultados, é considerada mais apropriada. Nesse contexto, as políticas deveriam ser analisadas em termos do seu impacto e das interações com desigualdades existentes. Esses efeitos podem ser divididos em duas categorias: gerais e específicos. Os efeitos gerais da política tornam-se evidentes quando aspectos específicos da mudança e conjuntos de respostas (observadas na prática) são agrupados e analisados. [...]. Tomados de modo isolado, os efeitos de uma política específica podem ser limitados, mas, quando efeitos gerais do conjunto de políticas de diferentes tipos são considerados, pode-se ter um panorama diferente (MAINARDES, 2006b, p. 54).

O último é o Contexto de Estratégia Política que "envolve a identificação de um conjunto de atividades sociais e políticas que seriam necessárias para lidar com as desigualdades criadas ou reproduzidas pela política investigada" (MAINARDES, 2006b, p. 55). Diante desse contexto, nosso estudo se propõe a considerar tanto as solicitações propostas pelos professores das unidades de Educação Escolar Indígena do Acre quanto os apontamentos realizados a respeito da concretização das políticas de promoção da Educação Escolar Indígena no Estado. 
Seguindo a concepção do Ciclo de Políticas, realçamos que as políticas serão sempre reinterpretadas pelos atores sociais, por isso sua efetivação depende de ir além da imposição, isto é, da criação de mecanismos para que os agentes rediscutam os múltiplos aspectos que envolvem o processo de formulação de determinada política, para que então reflitam junto a toda comunidade escolar indígena sobre as estratégias/possibilidades de concretização. Não se esquecendo de que nesses processos de compreensão e interpretação das políticas estão imersas as relações de tensionamentos políticos e disputas por interesses e poder.

A discussão que segue fora realizada a partir das informações coletadas através de documentação e do discurso de lideranças e professores indígenas no espaço público, bem como a partir da ressonância da atuação do movimento indígena por meio de matérias relacionadas à Educação Escolar Indígena publicadas na imprensa regional. As falas aqui reproduzidas não constituem algo finalizado, mas refletem o entendimento do interlocutor, naquele momento e ao ser expressa, como legítimo representante do movimento, e têm seu peso no processo de formulação de políticas públicas.

Identificamos a atuação de organizações indígenas e indigenistas na educação escolar do Acre, as quais revelam um histórico de influência na definição das políticas públicas educacionais indígenas. Trata-se da CPI, de natureza indigenista, e de um movimento indígena voltado às questões educacionais, a OPIAC, apontando os impasses entre elas e o Estado (SEE) na construção de políticas de educação.

As formas de atuação deste indigenismo caracterizaram-se por: reuniões com os índios nas aldeias; assessoria de profissionais não indígenas, especialmente do centro sul do Brasil, aos professores índios em cada uma de suas respectivas escolas; reunião dos indígenas na cidade em cursos de formação de professores; reunião para discussão de temas referentes às políticas públicas; apoio à criação, fortalecimento de organizações indígenas e financiamentos de pequenas atividades.

Como fruto dessa atuação, na década de 1990, uma forte demanda social proveniente de entidades indigenistas e do movimento de professores indígenas, na ocasião não reconhecido juridicamente, foi apresentada ao governo estadual. Na pauta, como primeira linha de ação, indicou-se a necessidade prioritária da formação de docentes. Conforme Silva, surge nesse momento a Coordenação de Educação Escolar Indígena como setor ligado aos demais programas da Coordenação de Ensino da Zona Rural da SEE/AC (SILVA, 2014). 
Em 2000, ocorreu o primeiro curso de formação de professores indígenas, promovido pela SEE/AC em parceria com a CPI/Acre, quando foi criado oficialmente o Programa Intercultural e Bilíngue no estado. Desse curso, participaram professores indígenas que até então não haviam passado por cursos de formação em Educação Escolar Indígena diferenciada.

Em meados dos anos 90, a necessidade de criação de uma entidade de representação política dos professores índios do Acre começou a ser discutida pelos professores participantes do Projeto de Educação. Assim, em 1997, esses professores criaram uma comissão para representar a política de Educação Escolar Indígena junto às entidades de apoio governamentais, e, em 2000, foi criada a Organização de Professores Indígenas do Acre (OPIAC), que tem os seguintes objetivos:

- Promover a Educação Escolar Indígena específica e diferenciada, de acordo com os interesses de cada etnia e divulgar junto às pessoas físicas, jurídicas, públicas, privadas e organizações não governamentais, nacionais e internacionais;

- Defender, perante os órgãos públicos, a implementação e melhoria de políticas educacionais e da legislação voltadas para a educação indígena especifica e diferenciada;

- Desenvolver ações com vistas a possibilitar condições adequadas à Educação Escolar Indígena diferenciada nas aldeias;

- Preservar, registrar e divulgar as formas de manifestação cultural, de conhecimentos e as histórias próprias de cada povo indígena;

- Representar e defender, judicial e extra-judicialmente, os interesses das comunidades e dos professores indígenas associados, quanto às questões relacionadas ao direito à EEI específica e diferenciada, bem como às questões culturais dos povos indígenas do estado do Acre (KAXINAWA, 2002, p. 150).

$\mathrm{Na}$ ata de fundação da OPIAC, encontra-se o registro de que ela nasceu da articulação de um grupo de professores indígenas que já acompanhavam e avaliavam ações de EEI. Foram realizados, entre 2000 e 2003, seminários em diálogo permanente com SEE, CPI/AC, MEC e algumas prefeituras, discutindo sobre cursos de formação do magistério indígena. Dessa forma, um conjunto de medidas legais fez com que essa modalidade educacional fizesse parte do rol de responsabilidades do Estado, desenvolvendo Programas de Formação de Professores Indígenas. A maior parte deles se desenvolveu no âmbito do Ensino Médio.

Embora com o apoio dessas organizações e assumida efetivamente pelo Estado, as políticas educacionais indígenas apontavam para sérias dificuldades, revelando um 
quadro marcado por questionamentos sobre a qualidade no atendimento dado às escolas indígenas e aos profissionais envolvidos no seu funcionamento. Parece-nos ser no momento de eleger prioridades que se observa a diferença, ou melhor, a falta dela. Uma boa educação não é feita apenas priorizando-se a construção de escolas, para citar um exemplo próximo. É importante observarmos o disposto no Art. 20 das Diretrizes Curriculares Nacionais para a Educação Escolar Indígena na Educação Básica:

Formar indígenas para serem professores e gestores das escolas indígenas deve ser uma das prioridades dos sistemas de ensino e de suas instituições formadoras, visando consolidar a Educação Escolar Indígena como um compromisso público do Estado brasileiro (BRASIL, 2012, p. 23).

Número significativo de egressos da Licenciatura Indígena do Acre, em suas falas, apontaram críticas também à baixa institucionalidade (ISA, 2011) em que a Educação Escolar Indígena está inserida. Os esforços de universalização do ensino público para os povos indígenas, promovidos pela Secretaria de Estado da Educação, Cultura e Esporte, não foram acompanhados por investimentos expressivos e satisfatórios para sua institucionalização.

O cenário da política educacional no Acre se encontra com déficit político, social e legal por não cumprir o disposto no PNE para o decênio 2001-2011, em capítulo sobre Educação Escolar Indígena. As implicações da inexistência das categorias professor indígena e escola indígena no sistema estadual são muito sérias. Para exemplificar, sob o aspecto da gestão escolar, mesmo as escolas indígenas que têm elaborado e reconhecidos seus projetos político-pedagógicos não estão autorizadas a certificar seus alunos, e, portanto, estes recebem documentos emitidos por escolas não indígenas.

Verificou-se certa indiferença política quando observamos a proposição de criação de um sistema próprio de Educação Escolar Indígena, pautado no documento final da I Conferência Nacional de Educação Escolar Indígena - CONEEI (2009) e referenciado na II CONEEI de 2018, ainda hoje sem realidade concreta.

Em nível nacional, boas esperanças vieram com a criação dos Territórios Etnoeducacionais ${ }^{2}$, realizada por meio do Decreto Presidencial no 6.861 de 27 de maio de

\footnotetext{
${ }^{2}$ Territórios Etnoeducacionais são áreas territoriais específicas que dão visibilidade às relações interétnicas construídas como resultado da história de lutas e reafirmação étnica dos povos indígenas, para a garantia de seus territórios e de políticas específicas nas áreas de saúde, educação e etnodesenvolvimento. A ideia de etnoterritório balisando políticas públicas voltadas aos povos indígenas é uma grande revolução
} 
2009. Surgiu aí a expectativa de que sua implementação no estado do Acre pudesse articular representantes do governo federal, dos sistemas de ensino, das organizações indígenas, das organizações indigenistas e da universidade, para o diálogo, proposição, planejamento, execução e avaliação participativa das ações (BRASIL, 2009).

Para acessar o processo de implementação, as secretarias de educação dos municípios, estados e do Distrito Federal devem apresentar as demandas pactuadas nas comissões gestoras dos TEEs, por meio do PAR - Plano de Ações Articuladas. Contudo, até o momento, apenas a etapa de consulta está em andamento em relação ao território etnoeducacional do estado (Kaxinawa), de modo que as informações sobre a ação da Coordenação Geral de Educação Escolar Indígena (CGEEI) no MEC não foram nada animadoras. Isso porque os poucos recursos financeiros, técnicos e humanos disponíveis seriam dirigidos nos próximos anos à consolidação dos territórios etnoeducacionais existentes.

Nos últimos anos, a formação de professores indígenas no magistério de nível médio tornou-se uma das questões mais preocupantes para as comunidades indígenas e instituições da sociedade civil, responsáveis por ações públicas no campo da Educação Escolar Indígena. Com a expansão do número de escolas e a consequente ampliação dos docentes, a formação destes não logrou êxito. Observamos descontinuidades na oferta e a ausência de um programa de formação definido pela Coordenação de Educação Escolar Indígena, seja para a obtenção da regularização da formação oferecida, seja para apreciação pública e acompanhamento.

Entre 2011 e julho de 2014, não foram realizados cursos de formação em magistério indígena e as justificativas para isso, apresentadas pela Secretaria de Estado de Educação e Esporte (SEE), são consideradas insatisfatórias e geralmente apontam como responsáveis o MEC/Fundo Nacional de Desenvolvimento da Educação. Uma liderança indígena, em maio de 2013, escreveu um texto afirmando que a formação de professores indígenas parece que ainda é uma dúvida dos governos, expressando sua preocupação com a formação docente.

histórica conceitual, na medida em que pode e dever mexer e mudar, sobretudo as estruturas de pensamento dos atores, dirigentes, gestores, e técnicos (Trecho do texto Territórios Etnoeducacionais: um novo paradigma na política educacional brasileira, apresentado por Gersem Baniwa na CONAE 2010 em Brasília). Disponível em $\quad<\quad$ http://6ccr.pgr.mpf.mp.br/institucional/grupos-detrabalho/educacao/documentos>>. Acesso em 24 de maio de 2018. 
Nós, indígenas, estamos sofrendo muito com esse mau planejamento do estado, que não garante firmar parcerias, nem disponibilizar recursos para a formação de professores indígenas. Vamos para o quarto ano consecutivo sem que os professores indígenas participem de cursos e ativem outros processos de formação, o que sabemos que prejudica, pois a formação é de fundamental importância para a qualidade da educação em nossas escolas ${ }^{3}$.

O governo estadual não moveu esforços necessários para a superação desse déficit no período, mostrando-se extremamente dependente de recursos federais e, ao mesmo tempo, desinteressado para captação de recursos. Assumir essa tarefa, com investimentos também próprios e negociação política com resultados junto ao MEC e à FUNAI, é o que se esperava como realização. Expectativa, inclusive, reforçada por posições públicas, como as expressas no documento "Carta do Amazonas", produzida durante reunião do Conselho Nacional de Secretários de Educação - CONSED sobre EEI, realizada na cidade de Manaus em Abril de 2005.

A falta de iniciativa para isso talvez não tenha considerado os efeitos negativos que teria sobre uma formação de professores indígenas em serviço, com expectativa e necessidades de participação anual em cursos, como também de viagens de assessoria para acompanhamento técnico de sua prática pedagógica. Se somarmos a isso os problemas anuais com os contratos e remuneração, sempre em atraso, e a insuficiência de material escolar, não nos surpreende os questionamentos que os próprios professores recebem de suas comunidades escolares. Diante desse quadro, os docentes indígenas, através da OPIAC, tomaram a iniciativa de procurar o apoio do Ministério Público Federal ${ }^{4}$.

Além da insuficiência de recursos financeiros, não houve a definição de uma política de formação para os professores indígenas, por parte Coordenação de Educação Indígena, que nos últimos anos tornou-se a única responsável pela formação inicial em magistério indígena. A política em questão implica na existência de diretrizes claras sobre a formação em magistério, com sua dimensão contextual e operacional fundamentadas e discutidas com a participação dos beneficiários e instituições governamentais e não governamentais atuantes na Educação Escolar Indígena.

\footnotetext{
${ }^{3}$ Trecho do texto "A formação de professores indígenas parece que ainda é uma dúvida dos governos", extraído de: <<http://avozdaapiwtxa.blogspot.com.br/>>. Acesso em: 30 de maio de 2018.

${ }^{4}$ Carta ao Ministério Público Federal de 7 de novembro de 2013, disponível na internet no endereço:xa.yimg.com/kq/groups/24050672/1408221428/name/Carta+ao+Ministério+Público.pdf
} 
Como fruto da pressão do movimento indígena mediante ação jurídica, entre julho e setembro de 2014, a SEE retomou as atividades de formação em Magistério Indígena (nível médio), realizadas no âmbito do MEC/PAR, Termo de Compromisso 6106/2012, através da Coordenação de Educação Escolar Indígena. Essa etapa da formação ocorreu depois de quatro anos após a última edição e constituiu o XI Curso de Formação de Professores Indígenas, reunindo 305 professores de diferentes povos indígenas do estado. Depois desse evento, não houve nenhuma ação de formação docente nos mesmos moldes da última edição, limitando-se a ações isoladas em comunidades indígenas.

Duas das proposições presentes no Relatório do XI Curso de Formação de Professores Indígenas, 2014, produzido coletivamente, merecem destaque: "reconhecer as categorias professor indígena e escola indígena; realizar concurso público específico". Em quase 20 anos de gestão da "Frente Popular do Acre" no executivo estadual, não fora realizado nenhum concurso público para provimento de cargos no magistério indígena, impondo todo esse tempo aos professores indígenas à renovação de contratos provisórios anualmente.

Para citar um exemplo recente de problemas decorrentes dessa situação, em novembro de 2014, o Ministério Público Federal, respondendo às solicitações feitas pelo coletivo de 22 associações, encabeçadas pela OPIAC, exigiu da SEE/AC maior celeridade no processo de contratação e entrada dos professores que trabalharam naquele ano na folha de pagamento do estado. A SEE reagiu apresentando possibilidades de renovação automática de contratos temporários entre outros procedimentos que seriam tomados para corrigir o problema, descartando ainda a opção de concurso. Todavia, até junho de 2015, não eram poucos os professores e outros profissionais indígenas de serviço de apoio escolar que não haviam assinado seu contrato com o estado. Portanto, professores e outros profissionais não possuem um plano de carreira, não incorporam gratificações de tempo de serviço e evolução funcional aos salários e não possuem todos os direitos trabalhistas de servidores efetivos.

A segunda proposição está relacionada à "infraestrutura física e material das escolas indígenas". Uma das maneiras utilizadas pela SEE/AC para demonstrar para as lideranças indígenas, suas associações e para as organizações da sociedade civil que mantém atenção para com a EEI consiste nas frequentes declarações sobre construção de escolas. De fato, até 2016, dados do SIMEC - Sistema Integrado de Monitoramento Execução e Controle do Ministério da Educação - mostravam que o Acre é o estado com o 
maior número de obras de escolas indígenas cadastradas. São 267 escolas que perfazem 39,67\% do total de escolas sendo construídas no Brasil 5 . Contudo, a ampliação dessa ação não foi acompanhada pela instalação e/ou melhoria de dois elementos importantes do processo: a consulta prévia sobre os projetos e o acompanhamento/monitoramento participativo das construções. Quando esses elementos não estão presentes, o risco de reclamações sobre problemas identificados aumenta consideravelmente, inaugurando processos jurídicos contra as empresas construtoras que inviabilizam a continuidade da obra ou sua revisão. Casos assim são apontados por várias lideranças indígenas.

Destacamos ainda dos discursos de lideranças e professores a morosidade na realização de ações que tornassem possível a regionalização da merenda escolar, isto é, a substituição de produtos fornecidos pelos comércios da cidade, pelo consumo da produção agroflorestal e criações existentes nas próprias aldeias. Entre os professores entrevistados, percebeu-se consenso de que a merenda escolar é inadequada, pois os alimentos fornecidos nem sempre são apreciados pelos alunos, além da dificuldade de distribuição por parte das secretarias de educação. A maioria das terras indígenas encontra-se distante das sedes dos municípios e o acesso quase sempre fluvial traz dificuldades em relação ao transporte da merenda, pois, segundo alguns professores, determinados produtos são entregues com prazos de validade curtos ou vencidos.

Apontamos algumas considerações finais, as quais demonstram que o teor das reivindicações expressa reflexões autônomas dos professores indígenas no que se refere às políticas educacionais, visando garantir um processo de construção conjunta das ações do estado através da cooperação e do diálogo que se propõem realizar com os órgãos públicos, favorecendo o fortalecimento de todos os atores envolvidos na EEI no estado. Torna-se evidente uma dimensão política que aspira por autonomia, mostrando capacidade de entender e nos fazerem entendermos que o modelo de educação que buscam pode, inclusive, ser diferente de todas as "receitas" experimentadas.

0 quadro apresentado traz questões que nos permitem perceber a existência de um campo de embates que se estabeleceu entre os povos indígenas e o estado. Essas tensões são construídas quando há a tentativa de se operar uma participação social dos primeiros na redefinição das ações públicas a eles direcionadas.

\footnotetext{
${ }^{5}$ Relatório no 01/2014/GT Construção/MEC. Situação das obras das escolas indígenas em março de 2014. Brasília: SECADI/CGEEI, 2014.
} 
Há uma preocupação na política educacional do Acre em atender aos povos indígenas. Todavia, esse esforço feito tem negligenciado as orientações legais que visam garantir o direito à participação efetiva no processo de tomada de decisões legislativas e administrativas que envolvam direitos coletivos desses povos.

Diante dos depoimentos, das ações empreendidas pelas organizações indígenas e indigenistas na luta por uma EEI de qualidade, nossa análise mostra que no Acre existem em diversas frentes do governo estadual e em algumas prefeituras exemplos de que o termo "participação" se reveste com significados de ação específica, evento, passividade. Torna-se importante, a partir das apropriações que o discurso governamental faz de categorias que até então eram de uso dos movimentos sociais, estabelecer uma distinção entre participação e consulta que não se confunde e que o direito a primeira não se resume a aplicação da segunda.

\section{Referências}

ACRE. Secretaria de Estado de Educação/Coordenação de Educação Escolar Indígena. Diagnóstico, Diretrizes e Metas da Educação Escolar Indígena no Acre, nov. 2009, mimeo.

. Resolução CEE/AC № 189/2013. Define normas gerais para implementação da Educação Escolar Indígena na Educação Básica, no âmbito do Estado do Acre. Rio Branco: 2013.

Relatório do XI Curso de Formação de Professores Indígenas: Documento Final com Reflexões e Proposições para Formação no Magistério Indígena. Rio Branco: 2014.

ANDRÉ, Marli. A pesquisa sobre formação de professores no Brasil-1990-1998. In: Linhares et al. Ensinar e aprender: sujeitos, saberes e pesquisa. Rio de Janeiro: DP\&A, 2002.

BRASIL. Ministério da Educação. Portaria $n^{\circ}$ 1.062, de 30 de outubro de 2013. Institui o Programa Nacional de Territórios Etnoeducacionais - PNTEE. Brasília, DF, 2013. . Ministério da Educação. Resolução CNE/CEB no 05/12. Diretrizes Curriculares Nacionais para a Educação Escolar Indígena na Educação Básica. Brasília: 2012.

. Constituição da República Federativa do Brasil: Diário Oficial da União de 05 de Outubro de 1988.

. Ministério da Educação. Lei no 9.394/96 de 20 de dezembro de 1996.

Estabelece as Diretrizes e Bases da Educação Nacional. Diário Oficial da União, Brasília, 23 de dezembro de 1996. 
2001.

. Ministério da Educação. Lei n 10.172. Plano Nacional de Educação. Brasília:

Presidência da República. Decreto-Lei № 6.861, de 27 de maio de 2009.

Disponível em: http://www.planalto.gov.br/ccivil 03/ ato2007-

2010/2009/decreto/d6861.htm. Acesso em: 30 Jan. 2019.

COMISSÃO PRÓ-ÍNDIO DO ACRE. Notas Técnicas sobre a Educação Escolar Indígena Programa de Educação e Pesquisa Indígena. Rio Branco, 2014.

GRUPIONI. Contextualizando o Campo da Educação de Professores Indígenas no Brasil. In:____ (Org.). Formação de Professores Indígenas: repensando trajetórias (Coleção Educação para Todos). Brasília: Ministério da Educação, SECAD, 2005.

Olhar longe, porque o futuro é longe - cultura, escola e professores indígenas no Brasil. 2008. 237f. Tese (Doutorado em Antropologia Social) - Universidade de São Paulo, São Paulo, 2008.

INSTITUTO SOCIAMBIENTAL (ISA) - Boletim de Notícias do ISA, Ano 17, nำ 49, Ago/nov de 2011. Disponível em: https://site-antigo.socioambiental.org/banco imagens/pdfs/boletim49.pdf. Acesso em 27 Jan. 2019.

KAXINAWÁ, JOAQUIM Paulo Maná. et al. Índios no Acre: história e organização. 2. ed. Rio Branco: CPI-AC, 2002.

MAINARDES, Jefferson. Abordagem do Ciclo de Políticas: uma contribuição para a análise de políticas educacionais. Educação \& Sociedade, Campinas, v. 27, n. 94, p. 4769, jan-abr/2006. (a)

A Abordagem do Ciclo de Políticas e suas Contribuições para a Análise da Trajetória de Políticas Educacionais. Atos de Pesquisa em Educação - PPGE/ME FURB, v. 1, no 2, p. 94-105, maio/ago. 2006. (b)

Análise de políticas educacionais: breves considerações teórico-metodológicas. Contrapontos - Volume 9, no 1 - pp.4-16 - Itajaí, jan/abr 2009.

ORGANIZAÇÃO DOS PROFESSORES INDÍGENAS DO ACRE (OPIAC): Ata da reunião com o Secretario de Educação do Acre, realizada em 30 de novembro de 2011. Rio Branco: 2011.

SILVA, José Alessandro Cândido da. Os Caminhos da Escola Indígena no Vale do Juruá

- Da Imposição à Ressignificação. Alemanha: Verlag Editora, 2014.

Docência Indígena no Extremo Oeste Brasileiro: uma experiência em andamento.

Revista Reflexão e Ação. Santa Cruz do Sul - Santa Catarina, v. 01, no especial, p. 76103, jan/jun 2013. 
SILVA, A.C.da. Educação escolar indígena: o cenário das políticas públicas no extremo ocidente do Brasil.

Recebido em Julho de 2019

Aprovado em Setembro de 2019

Publicado em Novembro de 2019 


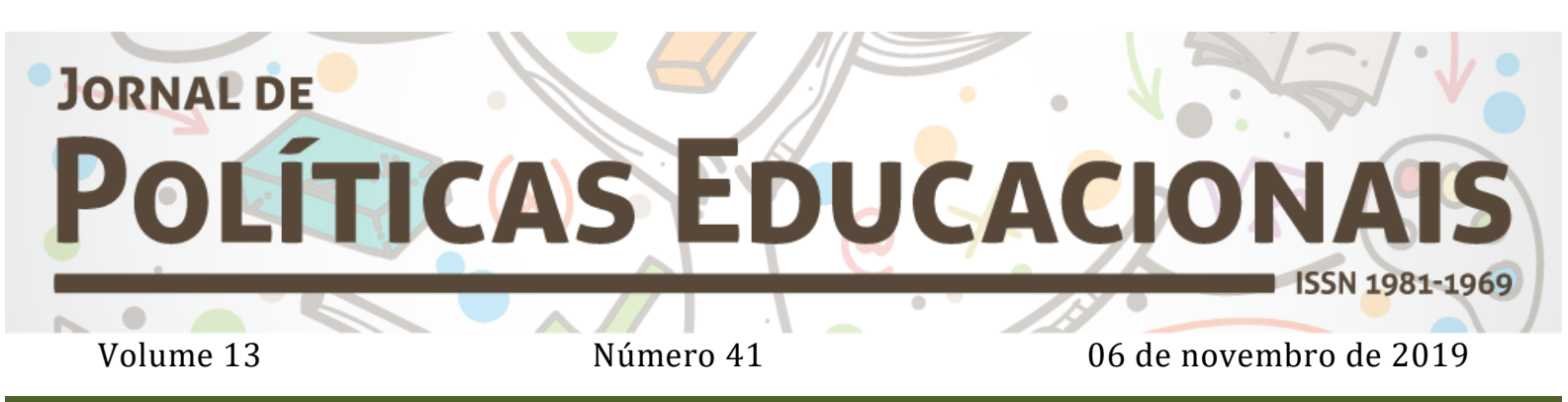

\title{
SORE RIGHIS RESERNED
}

O Copyright é retido pelo/a autor/a (ou primeiro co-autor) que outorga o direito da primeira publicação ao Jornal de Políticas Educacionais. Mais informação da licença de CreativeCommons encontram-se em http://creativecommons.org/licenses/by-nc-nd/2.5. Qualquer outro uso deve ser aprovado em conjunto pelo/s autor/es e pelo periódico.

JORNAL DE POLÍTICAS EDUCACIONAIS é uma publicação do Núcleo de Políticas Educacionais do Setor de Educação da Universidade Federal do Paraná - NuPE/UFPR, em consórcio com a Linha de Pesquisa em Políticas Educacionais do Programa de Pós-Graduação em Educação - PPGE/UFPR, que aceita colaboração, reservando-se o direito de publicar ou não o material espontaneamente enviado à redação. As colaborações devem ser enviadas ao NuPE/UFPR, conforme orientações contidas nas páginas do periódico na internet: http://revistas.ufpr.br/ipe.

\author{
Indexação: \\ BBE - Biblioteca Brasileira de Educação (MEC/INEP) \\ Clase (Base de Datos Bibliográfica de Revistas de Ciencias Sociales y Humanidades) \\ Diadorim - Diretório de Política de Acesso Aberto das Revistas Científicas Brasileiras (IBICT) \\ Google Scholar \\ Index Copernicus \\ Portal de Periódicos (CAPES) \\ SER - Sistema Eletrônico de Revistas da Universidade Federal do Paraná (SER/UFPR) \\ Sumários de Revistas Brasileiras (FUNPEC-RP) \\ DRJI - Directory of Research Journals Indexing
}

(Periódico integralmente disponível apenas em via eletrônica)

Jornal de Políticas Educacionais / Núcleo de Políticas Educacionais da Universidade Federal do Paraná -

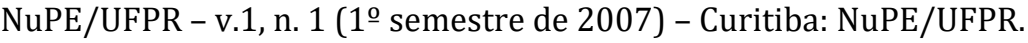

Volume 13, número 41 - Novembro de 2019

ISSN 1981-1969

1. Educação - Periódicos. 2. Política Educacional - Periódicos. I. NuPE/UFPR

Comitê Editorial:

Elisângela Scaff (UFPR)

Daniela Oliveira Pires (UFPR)

Conselho Editorial:

Andréa Barbosa Gouveia (UFPR - Brasil), Cesar Tello (Universidad Nacional Tres Febrero, Argentina), Fernanda Saforcada (Universidad de Buenos Aires - UBA - Argentina), Gladys Beatriz Barreyro (USP Brasil), Gustavo Enrique Fischman, (Arizona State University - USA), Jefferson Mainardes (UEPG - Brasil), João Ferreira de Oliveira (UFG - Brasil), Juca Gil (UFRGS - Brasil), Luiz Souza Júnior (UFPB - Brasil), Ney Cristina Monteiro de Oliveira (UFPA - Brasil), Nicolás Bentancur, (Universidad de la República de Uruguay), 
SILVA, A.C.da. Educação escolar indígena: o cenário das políticas públicas no extremo ocidente do Brasil.

Robert Verhine (UFBA - Brasil), Rosana Cruz (UFPI - Brasil), Rubens Barbosa Camargo (USP - Brasil), Sebastián Donoso Díaz (Universidad de Talca - Chile), TheresaAdrião (UNICAMP - Brasil), Vera Peroni (UFRGS - Brasil).

Créditos e Agradecimentos:

Revisão de Língua Portuguesa, Abstract e Resumen: PROGRAMA DE APOIO ÀS PUBLICAÇÕES CIENTÍFICAS PERIÓDICAS DA UFPR

Arte e diagramação: TIAGO TAVARES (tiagotav@gmail.com)

\author{
Jornal de Políticas Educacionais \\ Universidade Federal do Paraná \\ Setor de Educação \\ Núcleo de Políticas Educacionais - NuPE/UFPR \\ Avenida Sete de Setembro, 2645 \\ $2^{\circ}$ andar, Sala 213 \\ 80.230-010 - Curitiba - PR - Brasil \\ Tel.: 41-3535-6264 \\ jpe@ufpr.br \\ http://revistas.ufpr.br/jpe
}

